\title{
Evolution of practices in a French trauma centre: decrease in blood transfusions and fresh frozen plasma to red blood cell ratios.
}

Cyril PERNOD ( $\nabla$ cyril.pernod@chu-lyon.fr)

Groupement Hospitalier Edouard Herriot https://orcid.org/0000-0001-7151-6440

\section{Laurie Fraticelli}

Centre Hospitalier de Vienne Lucien Hussel

\section{Guillaume Marcotte}

Groupement Hospitalier Edouard Herriot

\section{Bernard Floccard}

Groupement Hospitalier Edouard Herriot

\section{Thibaut Girardot}

Groupement Hospitalier Edouard Herriot

\section{Clément Claustre}

Centre Hospitalier de Vienne Lucien Hussel

\section{Carlos El Khoury}

Centre Hospitalier de Vienne Lucien Hussel

\section{Maeva Durand}

Groupement Hospitalier Edouard Herriot

\section{Thomas Rimmelé}

Groupement Hospitalier Edouard Herriot

\section{Original research}

Keywords: fresh frozen plasma, tranexamic acid, transfusion, trauma induced coagulopathy, trauma injury, thromboelastometry

Posted Date: July 21 st, 2020

DOI: https://doi.org/10.21203/rs.3.rs-41760/v1

License: (c) (1) This work is licensed under a Creative Commons Attribution 4.0 International License. Read Full License 
Version of Record: A version of this preprint was published at Turkish Journal of Anaesthesiology and Reanimation on November 20th, 2021. See the published version at https://doi.org/10.5152/TJAR.2021.1229. 


\section{Abstract}

Background: Uncontrolled haemorrhage is still the leading cause of preventable death following trauma. Coagulation resuscitation strategies can be plasma-based or fibrinogen concentrate-based. The aim of this study was to describe the evolution of transfusion practices following the introduction of tranexamic acid (TXA) and ROTEM ${ }^{\circledR}$ in a trauma centre from a teaching hospital.

Methods: This is a single-centre, retrospective study at a Trauma Resuscitation Unit (TRU) from a French teaching hospital. All trauma patients aged 18 years or more and transfused with at least 4 red blood cells (RBCs) within 24 hours after trauma, from 2011 to 2016, were included. The primary objective was to analyse transfusion practices over this time period.

Assessment of the annual proportion of patients transfused with more than 4 RBCs at 24h, proportion of application of high fresh frozen plasma (FFP):RBC ratio ( $\geq 1: 2$ ), and proportion of administration of fibrinogen with ROTEM ${ }^{\circledR}$ protocol and TXA was performed. The secondary objectives aimed at assessing differences between populations according to the FFP:RBC ratio applied and compare all-cause mortality at D30.

Results: A total of 122 patients were included. Between 2011 and 2016, there was a significant decrease in the proportion of patients requiring at least 4 RBCs $24 \mathrm{~h}$ after trauma ( $\left.9 \% \mathrm{vs.} 3 \%, \mathrm{P}_{\text {trend }}<0.0001\right)$ as well as a decrease in the proportion of patients with a high FFP:RBC ratio $\left(86 \%\right.$ vs. $62 \%$ at $6 \mathrm{~h}, \mathrm{P}_{\text {trend }}=$ 0.0056 and $86 \%$ vs. $56 \%$ at $24 \mathrm{~h}, P_{\text {trend }}=0.0047$ ). After 2013 , fibrinogen was administered to more than $70 \%$ of patients and TXA to $100 \%$ of them. Adherence to the ROTEM ${ }^{\circledR}$ protocol for the administration of fibrinogen was significant. The observed mortality was lower than the predicted one, irrespective of FFP:RBC ratio.

Conclusion: From 2011 to 2016, an important evolution of practices occurred in the TRU including a decrease in the proportion of transfusions and use of high FFP:RBC ratios. The origin of these changes is multifactorial, likely including the systematic use of TXA and optimisation of the ROTEM ${ }^{\circledR}$ protocol for fibrinogen administration.

\section{Background}

Mortality from severe trauma continues to be a worldwide problem [1, 2], uncontrolled haemorrhage being a major cause of these preventable deaths [3]. Trauma-induced coagulopathy, which can occur early and increase mortality, is observed in one-third of patients with post-traumatic acute haemorrhage $[4,5]$. Management of trauma-induced coagulopathy is thus a key interventional target for trauma haemorrhage care. Resuscitation, in this context, aims at managing the haemostatic conditions before, during, and after damage control surgery in order to improve prognosis [5-8]. During the initial management stage of patients with expected massive haemorrhage, European guidelines recommend one of the two following strategies: Plasma [Fresh Frozen Plasma (FFP) or pathogen-inactivated plasma] 
in a plasma-Red Blood Cell (RBC) ratio of at least 1:2 (Grade 1B) or RBC and Fibrinogen concentrate guided by viscoelastic tests (Grade 1C) [9]. These guidelines are somehow discordant with French ones which recommend a systematic application of FFP:RBC ratio of at least 1:2 to $1: 1$, reporting that a decrease in mortality should be expected with the use of high FFP:RBC ratios [10].

Following the CRASH 2 study in 2010 [11], a generalisation of tranexamic acid (TXA) use was observed in our Trauma Resuscitation Unit (TRU) which coincided with an increase in the use of the ROTEM ${ }^{\circledR}$ protocol. Given the discordance of such an observation with the French guidelines in place at that time, we decided to assess our practices, with the hypothesis that although a reduction in transfusion volumes and application of high FFP:RBC ratios seemed to be occurring, this did not increase mortality.

The aim of the present study was thus to describe the evolution of transfusion practices in severely injured bleeding patients, between 2011 and 2016, in a TRU from a French teaching hospital. The primary objective was to analyse transfusion practices over time, measured by changes in blood transfusions, use of either high ( $\geq 1: 2)$ or low ( $<1: 2)$ FFP:RBC ratios, application of TXA, and administration of fibrinogen according to the ROTEM $\AA$ protocol. Patient characteristics and mortality between high $v s$. low FFP:RBC ratio groups were also compared as secondary objectives.

\section{Methods}

\section{Data source}

Covering a population of 3 million inhabitants and about $25000 \mathrm{~km}^{2}$ of rural and urban areas of the Rhône-Alpes region in France, the RESUVal system (Réseau des Urgences de la Vallée du Rhône) gathers physicians around common guidelines and actively participates in education and evaluation of professional practices. Among the 65 health institutions of the Rhône-Alpes region, 37 public and private hospitals belong to the RESUVal system, including several trauma centres. Among the evaluation tools available, the prospective observational Trauma-System registry $[12,13]$ reports, since 2011 , all adult patients ( $\geq 18$ years old) with at least one traumatic lesion and managed by emergency medical services that are part of the RESUVal area (See Supplementary File 1). Within this system, the physician in charge of pre-hospital management is the first one who requests consent on eligible patients. Data for this prospective registry are collected in a structured and standardised case report form, throughout the care management pathway, from management by emergency medical services, to the emergency department or the TRU.

\section{Study design and population selection}

This is a retrospective study based on data obtained from the Trauma-System registry in a single TRU from a French teaching hospital. The TRU is a dedicated resuscitation room within the intensive care unit department which benefits from a dedicated team composed of an intensivist, the trauma leader accompanied by a resident, a visceral surgeon, an orthopaedic surgeon, a nurse, and an assistant nurse. According to both European and French guidelines [9, 10], TXA was administered as early as possible, 
within $3 \mathrm{~h}$ after injury, with a loading dose of $1 \mathrm{~g}$ infused over $10 \mathrm{~min}$, followed by an intravenous infusion of $1 \mathrm{~g}$ over $8 \mathrm{~h}$. When indicated, ROTEM ${ }^{\circledR}$ protocol (thromboelastometry, Tem International, Munich, Germany) was performed upon admission to the TRU. Fibrinogen concentrate was administered at a dose of $3 \mathrm{~g}$ either when indicated by the ROTEM ${ }^{\circledR}$ protocol, based on FIBTEM A10 and EXTEM A15 parameters (See Supplementary File 2), or when plasma fibrinogen levels were less than $1.5-2.0 \mathrm{~g} / \mathrm{l}$. ROTEM ${ }^{\circledR}$ could be performed again if necessary. At the time of the study, FFP administration was either guided by laboratory coagulation screening parameters (Prothrombine time $<50 \%$ ) and/or viscoelastic evidence of a coagulation factor deficiency using ROTEM $\$$ protocol (See Supplementary File 2) in accordance with European guidelines, or administered probabilistically depending on the number of RBCs according to French guidelines $[9,10]$. Massive transfusion was defined as the administration of at least 10 RBCs within $24 \mathrm{~h}$ after trauma [14]. Biological coagulopathy was defined as Prothrombin Time ratio (PTr) $>1.2$ according to Davenport's coagulopathy definition [15].

All patients managed from March 2011 to December 2016 and transfused with at least 4 RBCs within the first $24 \mathrm{~h}$ after trauma were included. Cross-validation was performed with the French blood services (Etablissement Français du Sang) to validate the population selected, collect missing values if needed, and to recount the number and time of RBC and FFP delivery for each patient. Data were finally completed by consulting electronic medical records to collect the date of death when the patient died at the hospital after his transfer from the TRU to another service.

\section{Statistical analyses}

For univariate statistics, categorical data were expressed as frequencies and percentages, continuous data by median and interquartile range [IQR]. Pearson's chi-squared tests were performed for categorical data and Wilcoxon non-parametric rank sum tests for continuous data. The $p$-values were estimated by comparing the Z-score obtained with the reduced normal centred law, and considered significant when $\mathrm{p}$ value $<0.05$. The linear trend of frequencies of categorical variables were tested using a CochranArmitage test for trend ( $\mathrm{p}$-trend) and considered significant when $\mathrm{p}$-trend $<0.05$. For survival analysis, the TRISS (Trauma Revised Injury Severity Score) was evaluated [16]. It represents the best predictive index of intra-hospital at D30 mortality $[17,18]$. Predicted mortality was evaluated using the nTRISS (i.e TRISS normalised to respiratory rate) [17] and compared to observed mortality [19]. The change in population characteristics over time was tested using a univariate linear regression for continuous variables [age, ISS (Injury Severity Score) [20], MGAP (Mechanism Glasgow Age Pressure) score [21, 22], nRTS (normalised Revised Trauma Score) [23] and nTRISS] and a univariate logistic regression for qualitative variables (mortality at 30 days) with the year of admission as explanatory variable. All statistical analyses were performed using $\mathrm{R}{ }^{\circledR}$ 3.4.2 Software ( $\mathrm{R}$ foundation for Statistical Computing, Vienna, Austria).

\section{Results}

\section{Study population}


Over the 70-month study period, 122 patients were included. There were 310 patients admitted to the trauma centre and transfused within 24 hours. Of these, 185 patients were excluded because they received less than 4 RBCs at $24 \mathrm{~h}$. Another 3 files could not be identified (Fig. 1).

Among the study population, $25 \%$ of patients underwent massive transfusion ( $\geq 10$ RBCs at $24 \mathrm{~h}$ ) and $67 \%$ received more than 6 RBCs in the first $24 \mathrm{~h}$ of trauma occurrence. Blunt trauma represented $84 \%$ of the studied population and $74 \%$ of patients had biological coagulopathy on admission (Table 1 ).

Analysis of changes in patient characteristics showed no significant changes over the time period studied in the annual distribution of patients according to their ISS (Fig. 2) nor their nRTS, nTRISS, age, and D30 mortality. A significant decrease in the annual median MGAP score between 2011 (22 [17-27]) and 2016 (19 [13-23], $p=0.0353)$ was found.

\section{Evolution in transfusion practices}

The proportion of patients transfused $\geq 4$ RBCs within the first $24 \mathrm{~h}$ of trauma significantly decreased between 2011 and 2016 when compared to either the total annual admissions to the TRU $\left(9-3 \%, P_{\text {trend }}<\right.$ 0.0001 ; Fig. 3a) or the total proportion of patients transfused within the first $24 \mathrm{~h}$ after trauma in the TRU $\left(55-34 \%, P_{\text {trend }}=0.0027\right.$; Fig. 3b).

The proportion of a high FFP:RBC ratio significantly decreased between 2011 and 2016, at $6 \mathrm{~h}(86-62 \%$, $\left.P_{\text {trend }}=0.0056\right)$ and $24 \mathrm{~h}\left(86-56 \%, P_{\text {trend }}=0.0047\right.$; Fig. 4).

The administration of TXA within 3 hours after trauma (on-scene, or hospital administration) increased significantly over the time course of the study. After 2013, TXA was administered to the entire cohort of patients (Fig. 5).

Fibrinogen concentrate was administered in $73 \%$ (89/122) of the population. Of these, $63 \%(56 / 89)$ received only one supplementation of $3 \mathrm{~g}, 20 \%$ (18/89) received a second dose of 1.5 to $3 \mathrm{~g}$ and only $15 \%$ $(13 / 89)$ received more than $6 \mathrm{~g}$. The proportion of patients receiving fibrinogen concentrate did not change significantly over the study period. The administration of fibrinogen concentrate was significantly associated to the indication given by the ROTEM ${ }^{\circledR}$ protocol used in the TRU or by plasma fibrinogen levels when ROTEM ${ }^{\circledR}$ was not performed (Table 2).

\section{High vs. low FFP:RBC ratio: patient characteristics and mortality}

High FFP:RBC ratio groups were characterised by significantly higher proportion of massive transfusions

( $\geq 10$ RBCs at $24 \mathrm{~h}$ ), and $\geq 6$ RBCs administrations at $24 \mathrm{~h}$ as well as higher median PTr and median INR than the low ratio groups, at both $6 \mathrm{~h}$ and $24 \mathrm{~h}$ (Table 3 ). There was, however, no significant difference between groups in terms of anticoagulants and antiplatelet agents administered, blunt trauma, severe cranial trauma (Glasgow score $\leq 8$ ), administration of TXA, or haemostasis procedure needed (embolisation or surgery). There was also no significant difference for the mean severity scores such as 
MGAP, nRTS, ISS, nTRISS. The observed mortality at D30 was significantly higher for the high ratio group at $6 \mathrm{~h}[37 \%(\mathrm{n}=30) v s .15 \%(\mathrm{n}=5), \mathrm{p}=0.0313]$; a trend towards a higher mortality was found in the high ratio group at $24 h$ [33\% $(n=30)$ vs. $19 \%(n=6), p=0.1842]$. Statistical analysis using $n$-TRISS revealed that in all groups (high ratio and low ratio, at $6 \mathrm{~h}$ and $24 \mathrm{~h}$ ), observed mortality was significantly lower than predicted mortality (Table 4).

\section{Discussion}

The present study showed a sharp decline in the proportion of patients requiring at least 4 RBCs within the first $24 \mathrm{~h}$ after trauma and a significant decrease in the proportion of high FFP:RBC ratio administration at $6 \mathrm{~h}$ and $24 \mathrm{~h}$. From 2011 onwards, an increasing number of the study population received TXA, reaching $100 \%$ compliance in 2014. The proportion of patients receiving fibrinogen also appeared to increase over time, although not significantly. It seemed that good adherence to the ROTEM ${ }^{\circledR}$ protocol was observed since the administration of fibrinogen concentrate was significantly associated with the indication given by the ROTEM ${ }^{\circledR}$ protocol, in univariate analysis. Although observed mortality was higher in the high FFP:RBC ratio group than in the low ratio group, the proportion of observed deaths, when compared to expected deaths, was significantly lower, irrespective of FFP:RBC ratio type or time of application.

The reduction in the proportion of transfused patients and volumes administered, as well as the reduction in high FFP:RBC ratios over the study period, could be due to improvement in the overall therapeutic management strategy as depicted by the optimisation of radioembolisation techniques [24] and establishment of a dedicated trauma team [25-27]. Similar results have also very recently been reported by another French trauma centre [28]. Of note, there was no significant change in the annual proportion of patients who underwent embolisation and/or haemostatic surgical management (data not shown). Another hypothesis is the possible decrease in patient severity over time reported in the area, due to improvement in road safety measures [29]. However, patient severity in the present study was stable. Indeed the most robust injury severity score, ISS, did not change over time, similarly to the nRTS, nTRISS, age, and D30 mortality. Although there was a decrease in the median MGAP score between 2011 and 2016 , this change is not clinically relevant as the scores remained within the same range (19-23) of the intermediate risk group. Thus a decrease in patient severity was not observed herein, likely reflecting a recruitment bias, since the cohort consisted only of patients admitted to the TRU and transfused $\geq 4$ RBCs. Indeed, although there may be fewer severe patients, the more severe ones are always referred to the TRU.

Due to the study design, it is difficult to assess the impact of systematic TXA administration or the use of a ROTEM ${ }^{\circledR}$ protocol on the observed changes. In the CRASH 2 population study, TXA reduced all-cause mortality by $1.5 \%$ (from $16-14.5 \%$ ) and reduced the risk of death due to bleeding (4.9\% vs $5.7 \%$; relative risk $0.85,95 \% \mathrm{Cl}[0.76 ; 0.96] ; p=0.0077)$. However, the benefit of TXA on mortality is probably

underestimated by the low proportion of patients transfused in this study (50\% of the population) [11]. Moreover, another recent study showed that early pre-hospital administration of TXA led to clot 
stabilisation and a reduction in fibrinolytic activity as measured by ROTEM ${ }^{\circledR}$ [30]. To the best of our knowledge, no study has specifically demonstrated the benefit of TXA in reducing transfusions in traumatised patients. However, standardisation of TXA administration showed a significant benefit in the context of hip and knee arthroplasty, including reductions in: perioperative haemoglobin decrement (20\%), patients transfused (45\%), and number of units transfused per patient (62\%) [31]. Concerning the possible impact of using a ROTEM ${ }^{\circledR}$ protocol for the administration of coagulation factors, a retrospective study with trauma patients found significantly lower observed mortality when compared to the mortality predicted by the TRISS $(24.4 \%$ vs $33.7 \%$; $p=0.032)$ [32]. Another retrospective study on cardiovascular surgery patients showed that the use of a ROTEM ${ }^{\circledR}$ protocol resulted in a reduction of blood product transfusions but did not influence mortality [33]. Of important note, ROTEM ${ }^{\circledR}$ was introduced in 2004 in the TRU but its use by the physician was improved when its relocation to the haemostasis laboratory occurred in 2010. It would have been interesting to compare the present data to those of previous years but, unfortunately, the RESUVal database did not include data prior to this period.

The proportion of observed deaths, when compared to expected deaths, was significantly lower, irrespective of FFP:RBC ratio type or time of application. These results are discordant with French guidelines [10] reporting that a decrease in mortality should be expected with the use of high FFP:RBC ratios. These recommendations are largely based on the findings of the Banghu meta-analysis [34] indicating a $51 \%$ mortality reduction with the use of high FFP:RBC ratios. If this were the case, we would have expected an increase in observed mortality compared to expected mortality for the low FFP:RBC ratio group. Herein, the decrease in proportion of observed deaths was also not related to time of application for high FFP:RBC ratios. This again is not in line with the PROMMTT study [35] that showed a better survival for patients when high FFP:RBC ratios were applied at $6 \mathrm{~h} v s$. $24 \mathrm{~h}$. These results suggest an improvement in patient prognosis due to overall medical management, regardless of the FFP:RBC ratio applied. Importantly, the study population included a low proportion of haemodynamically unstable patients, few penetrating trauma cases, and less anticoagulant or antiplatelet treatments than other study populations. Nevertheless, according to Davenport's coagulopathy definition [15], the present cohort included a particularly large proportion of patients with trauma induced coagulopathy $(74 \%$ of $P T r \geq 1.2$ on admission).

Despite the decline in use of plasma reported here, more than half of the patients still benefited from high ratio administration in 2016, suggesting the importance of plasma transfusion in the management of trauma patients. When indicated, the efficacy of plasma administration would certainly be improved by early application through the use, for instance, of lyophilised plasma which is now available [36].

\section{Limitations}

This study has a number of limitations. First, this is a retrospective study in its design, although the collection of information was done in a prospective manner using a computerised and centralised database. These data allowed us to objectively highlight the change in the transfusion practices in reallife conditions. Second, the study included a small patient population due to both the single-centre design 
of the study and the short period of inclusion. However, a multi-centre study would not have allowed investigation of the practices of the present TRU, which was the primary objective of the current study. Moreover, including patients before 2011 would have made the analysis difficult due to the extreme diversity in clinical practices prior to that time. We could have included more patients by decreasing the transfusion volume of inclusion, but it would have been less relevant for the analysis of the FFP:RBC ratios. Third, the groups high $v s$. low ratios were not similar. Due to the design of the study and the small number of patients, multivariate analysis, to eliminate comparability bias between groups, could not be performed. Groups were therefore compared to themselves using the n-TRISS score. Lastly, adherence to the ROTEM ${ }^{\circledR}$ protocol did not reach $100 \%$ over the study period. However, a $75 \%$ adherence can be considered good given that a multi-centre study showed that only $24 \%$ of patients in intensive care units received fully compliant care [37]. Moreover, the majority of protocol deviations occurred in 2011, at the start of protocol implementation.

\section{Conclusion}

From 2011 to 2016, an important evolution of practices occurred in the TRU including a decrease in the proportion of transfusions and use of high FFP:RBC ratios. The origin of these changes is multifactorial, likely including the systematic use of TXA and optimisation of the ROTEM® protocol for fibrinogen administration.

\section{Abbreviations}

CCTIRS: Comité consultatif sur le traitement de l'information en matière de recherche scientifique; CNIL: Commission Nationale de l'Informatique et des Libertés; FFP: Fresh Frozen Plasma; ISS: Injury Severity Score; MGAP: Mechanism Glasgow Age Pressure; nTRISS: TRISS normalised to respiratory rate; nRTS: normalised Revised Trauma Score; PTr: Prothrombin Time ratio; RBCs: Red Blood Cells; RESUVal system: Réseau des Urgences de la Vallée du Rhône; TRISS: Trauma Revised Injury Severity Score; TRU: Trauma Resuscitation Unit; TXA: Tranexamic acid.

\section{Declarations}

\section{Acknowledgements}

We would like to thank Giovanna Cannas (MD) and her team for access to the haemovigilance files as well as the ICU secretaries and Véréna Landel (PhD) for her help with the manuscript preparation.

\section{Authors' contributions}

All the authors have approved the final version to be published and agree to be accountable for all aspects of the work. CP, LF, BF, GM, TG, TR designed the methodology and have interpreted the results. CP, LF, CC and MD contributed to the data acquisition. LF, CC and CEK provided the statistical analysis. CP, LF, GM, FB wrote the draft and TG, CC, MD, CEK and TR revised it critically for important intellectual content. 


\section{Funding}

The RESUVal Network is funded by the Regional Agency for Health from the Auvergne-Rhône-Alpes region (Agence Régionale de Santé Auvergne-Rhône-Alpes).

\section{Availability of data and materials}

The datasets generated during and/or analyzed during the current study are available from the corresponding author on reasonable request.

\section{Ethics approval and consent to participate}

The Trauma-System registry received approval from the National Commission for Liberties and Data Protection (Commission Nationale de I'Informatique et des Libertés, CNIL, reference number DE-2012059) and received approval from the Advisory Committee on the Treatment of Research Information (Comité consultatif sur le traitement de l'information en matière de recherche scientifique, CCTIRS, reference number: 15.368). This study was approved by an ethics committee and registered under the reference number 17-060 in the CNIL register. In accordance with the French law, all patients included were informed of their participation and could decline the use of their data if they wished.

\section{Competing interests}

Not applicable.

\section{References}

1. Murray CJ, Lopez AD. Alternative projections of mortality and disability by cause 1990-2020: Global Burden of Disease Study. Lancet Lond Engl. 1997;349(9064):1498-504.

2. Lendrum RA, Lockey DJ. Trauma system development. Anaesthesia. 2013;68(1):30-9. Suppl.

3. Tien HC, Spencer F, Tremblay LN, Rizoli SB, Brenneman FD. Preventable deaths from hemorrhage at a level I Canadian trauma center. J Trauma. 2007;62(1):142-6.

4. Floccard B, Rugeri L, Faure A, Saint Denis M, Boyle EM, Peguet O, et al. Early coagulopathy in trauma patients: an on-scene and hospital admission study. Injury. 2012;43(1):26-32.

5. Maegele M, Lefering R, Yucel N, Tjardes T, Rixen D, Paffrath T, et al. Early coagulopathy in multiple injury: an analysis from the German Trauma Registry on 8724 patients. Injury. 2007;38(3):298-304.

6. Brohi K, Singh J, Heron M, Coats T. Acute traumatic coagulopathy. J Trauma. 2003;54(6):1127-30.

7. MacLeod JBA, Lynn M, McKenney MG, Cohn SM, Murtha M. Early coagulopathy predicts mortality in trauma. J Trauma. 2003;55(1):39-44.

8. Brohi K, Cohen MJ, Davenport RA. Acute coagulopathy of trauma: mechanism, identification and effect. Curr Opin Crit Care. 2007;13(6):680-5. 
9. Rossaint R, Bouillon B, Cerny V, Coats TJ, Duranteau J, Fernández-Mondéjar E, et al. The European guideline on management of major bleeding and coagulopathy following trauma: fourth edition. Crit Care. 2016;12(20):100.

10. Duranteau J, Asehnoune K, Pierre S, Ozier Y, Leone M, Lefrant J-Y. Recommandations sur la réanimation du choc hémorragique. Anesthésie Réanimation. 2015;1(1):62-74.

11. Shakur H, Roberts I, Bautista R, Caballero J, Coats T, Dewan Y, et al. CRASH-2 trial collaborators. Effects of tranexamic acid on death, vascular occlusive events, and blood transfusion in trauma patients with significant haemorrhage: a randomised, placebo-controlled trial. Lancet. 2010;376(9734):23-32.

12. Bouzat P, David JS, Tazarourte K. French regional trauma network: the Rhone-Alpes example. $\mathrm{Br} \mathrm{J}$ Anaesth. 2015;114(6):1004-5.

13. David JS, Bouzat P, Raux M. Evolution and organisation of trauma systems. Anaesth Crit Care Pain Med. 2019;38(2):161-7.

14. Como JJ, Dutton RP, Scalea TM, Edelman BB, Hess JR. Blood transfusion rates in the care of acute trauma. Transfusion. 2004;44:809-13.

15. Davenport R, Manson J, De'Ath H, Platton S, Coates A, Allard S, et al. Functional definition and characterization of acute traumatic coagulopathy. Crit Care Med. 2011;39(12):2652-8.

16. Boyd CR, Tolson MA, Copes WS. Evaluating trauma care: the TRISS method. Trauma Score and the Injury Severity Score. J Trauma. 1987;27(4):370-8.

17. Munter L de, Polinder S, Lansink KWW, Cnossen MC, Steyerberg EW, Jongh MAC de. Mortality prediction models in the general trauma population: A systematic review. Injury. 2017;48(2):221-9.

18. Bouzat P, Legrand R, Gillois P, Ageron F-X, Brun J, Savary D, et al. Prediction of intra-hospital mortality after severe trauma: which pre-hospital score is the most accurate? Injury. 2016;47(1):14-8.

19. Flora JD. A Method for Comparing Survival of Burn Patients to a Standard Survival Curve. J Trauma Acute Care Surg. 1978;18(10):701.

20. Baker SP, O'Neill B, Haddon W, Long WB. The injury severity score: a method for describing patients with multiple injuries and evaluating emergency care. J Trauma. 1974;14(3):187-96.

21. Sartorius D, Le Manach Y, David J-S, Rancurel E, Smail N, Thicoïpé M, et al. Mechanism, glasgow coma scale, age, and arterial pressure (MGAP): a new simple prehospital triage score to predict mortality in trauma patients. Crit Care Med. 2010;38(3):831-7.

22. Rehn M, Perel P, Blackhall K, Lossius HM. Prognostic models for the early care of trauma patients: a systematic review. Scand J Trauma Resusc Emerg Med. 2011;20(19):17.

23. Champion HR, Sacco WJ, Copes WS, Gann DS, Gennarelli TA, Flanagan ME. A revision of the Trauma Score. J Trauma. 1989;29(5):623-9.

24. Chakraverty S, Zealley I, Kessel D. Damage control radiology in the severely injured patient: what the anaesthetist needs to know. $\mathrm{Br} J$ Anaesth. 2014;113(2):250-7. 
25. Brindley PG. I. Improving teamwork in anaesthesia and critical care: many lessons still to learn. $\mathrm{Br} \mathrm{J}$ Anaesth. 2014;112(3):399-401.

26. Howell SJ. I. Advances in trauma care: a quiet revolution. Br J Anaesth. 2014;113(2):201-2.

27. Tiel Groenestege-Kreb D, van Maarseveen O, Leenen L. Trauma team. Br J Anaesth. 2014;113(2):258-65.

28. Guth C, Vassal O, Friggeri A, Wey P-F, Inaba K, Decullier E, et al. Effects of modification of trauma bleeding management: A before and after study. Anaesth Crit Care Pain Med 2019; 23.

29. Eurostats. Décès dus aux accidents de transport. [Internet] 2017. Available from http://ec.europa.eu/eurostat/tgm/table.do?tab=table\&plugin=1\&language=fr\&pcode=tps 00165 .

30. Stein P, Studt J-D, Albrecht R, Müller S, von Ow D, Fischer S, et al. The Impact of Prehospital Tranexamic Acid on Blood Coagulation in Trauma Patients. Anesth Analg. 2018;126(2):522-9.

31. Demos HA, Lin ZX, Barfield WR, Wilson SH, Robertson DC, Pellegrini VD. Process Improvement Project Using Tranexamic Acid Is Cost-Effective in Reducing Blood Loss and Transfusions After Total Hip and Total Knee Arthroplasty. J Arthroplasty. 2017;32(8):2375-80.

32. Schöchl H, Nienaber U, Hofer G, Voelckel W, Jambor C, Scharbert G, et al. Goal-directed coagulation management of major trauma patients using thromboelastometry (ROTEM)-guided administration of fibrinogen concentrate and prothrombin complex concentrate. Crit Care. 2010;14(2):R55.

33. Görlinger K, Dirkmann D, Hanke AA, Kamler M, Kottenberg E, Thielmann M, et al. First-line therapy with coagulation factor concentrates combined with point-of-care coagulation testing is associated with decreased allogeneic blood transfusion in cardiovascular surgery: a retrospective, single-center cohort study. Anesthesiology. 2011;115(6):1179-91.

34. Bhangu A, Nepogodiev D, Doughty H, Bowley DM. Meta-analysis of plasma to red blood cell ratios and mortality in massive blood transfusions for trauma. Injury. 2013;44(12):1693-9.

35. Holcomb JB, Junco DJ del, Fox EE, Wade CE, Cohen MJ, Schreiber MA, et al. The Prospective, Observational, Multicenter, Major Trauma Transfusion (PROMMTT) Study: Comparative Effectiveness of a Time-Varying Treatment With Competing Risks. JAMA Surg 2013;148(2):127-36.

36. Nguyen C, Bordes J, Cungi P-J, Esnault P, Cardinale M, Mathais Q, et al. Use of French lyophilized plasma transfusion in severe trauma patients is associated with an early plasma transfusion and early transfusion ratio improvement. J Trauma Acute Care Surg. 2018;84(5):780-5.

37. Leone M, Ragonnet B, Alonso S, Allaouchiche B, Constantin J-M, Jaber S, et al. Variable compliance with clinical practice guidelines identified in a 1-day audit at 66 French adult intensive care units. Crit Care Med. 2012;40(12):3189-95.

\section{Tables}

Table 1. Population characteristics. 
Direct admission from on-scene to the TRU, $\mathrm{n}(\%)$

Median time between on-scene ambulance arrival and arrival to the TRU [IQR], $80[60-118]$ minutes

Blunt trauma, $\mathrm{n}(\%)$

$102(84)$

Road traffic accident, $\mathrm{n}(\%)$

$54(44)$

Fall, $\mathrm{n}(\%)$

Aggression, $\mathrm{n}(\%)$

$8(7)$

Other/unknown, n (\%)

$39(32)$

Median age [IQR], years

39 [27-51]

Sex (male), $\mathrm{n}(\%)$

$71(58)$

Pre-hospital mean blood pressure $<65 \mathrm{mmHg}, \mathrm{n}(\%)$

$27(22)$

Pre-hospital Glasgow < 8, n (\%)

$51(42)$

Pre-hospital Sp02<95\%, n (\%)

$26(21)$

Pre-hospital severity scale level $59(48)$

- Level 2, n (\%) $49(40)$

- Level 3, n (\%)

Haemoglobin $<9 \mathrm{~g} / \mathrm{dl}$ on-scene, $\mathrm{n}(\%)$

Haemoglobin $<9 \mathrm{~g} / \mathrm{dl}$ at TRU admission, $\mathrm{n}(\%)$

Anticoagulant or antiplatelet treatment as usual treatment, $\mathrm{n}(\%)$

TRU: Trauma Resuscitation Unit

PTr: Prothrombin Time ratio

MGAP: Mechanism Glasgow Age Pressure

nRTS: normalized Revised Trauma Score

ISS : Injury Severity Score

SAPS II: Simplified Acute Physiology Score II

RBC: Red blood Cell

IQR: Interquartile Range 


\begin{tabular}{|ll|}
\hline Total population & $\mathrm{n}=122$ \\
\hline Trauma induced coagulopathy at admission = PTr > 1.2, $\mathrm{n}(\%)$ & $90(74)$ \\
\hline Radioembolisation, $\mathrm{n}(\%)$ & $40(33)$ \\
\hline Surgery, $\mathrm{n}(\%)$ & $76(62)$ \\
\hline Median MGAP [IQR], points & $22(15-26)$ \\
\hline Median nRTS [IQR], points & $6.4(4.1-$ \\
\hline Median ISS [IQR], points & $7.8)$ \\
\hline Median SAPS II [IQR], points & $38(25-50)$ \\
\hline RBCs $\geq 6$ at 24 h, $\mathrm{n}(\%)$ & $54(40-71)$ \\
\hline RBCs $\geq 10$ at 24 h, $\mathrm{n}(\%)$ & $84(67)$ \\
\hline TRU: Trauma Resuscitation Unit & $30(25)$ \\
\hline PTr: Prothrombin Time ratio & \\
\hline MGAP: Mechanism Glasgow Age Pressure & \\
\hline nRTS: normalized Revised Trauma Score & \\
\hline ISS : Injury Severity Score & \\
\hline SAPS II: Simplified Acute Physiology Score II & \\
\hline RBC: Red blood Cell & \\
\hline IQR: Interquartile Range & \\
\hline
\end{tabular}

Table 2. Proportion of respected vs. not respected fibrinogen concentrate indication according to ROTEM® protocol*. 


\begin{tabular}{|llll|}
\hline Fibrinogen concentrate indication & Respected & $\begin{array}{l}\text { Not } \\
\text { respected }\end{array}$ & $\mathbf{p}^{1}$ \\
\hline ROTEM $\circledast$ performed (97 patients), $\mathrm{n}(\%)$ & $77(79)$ & $21(21)$ & 0.0003 \\
\hline $\begin{array}{l}\text { ROTEM }{ }^{8} \text { performed and plasma fibrinogen level (122 } \\
\text { patients), } \mathrm{n}(\%)\end{array}$ & $93(76)$ & $29(24)$ & 0.0001 \\
\hline Respected: indicated and administered or not indicated and not administered & \\
\hline Not respected: indicated and not administered or not indicated and administered & \\
\hline $\begin{array}{l}\mathrm{p}^{1} \text { : Computed from the contingency table of fibrinogen indication and fibrinogen administration using } \\
\text { a Pearson's chi-squared test. }\end{array}$ & \\
\hline *Cf appendix & & \\
\hline
\end{tabular}

Table 3. Low vs. high ratio group characteristics.

\begin{tabular}{|c|c|c|c|}
\hline Variables at $6 \mathrm{~h}$ & Low ratio $(\mathrm{N}=34)$ & High ratio $(\mathrm{N}=81)$ & $\mathbf{p}$ \\
\hline $\begin{array}{l}\text { RBCs } \geq 10 \text { at } 24 \mathrm{~h}, \mathrm{n}(\%) \\
\text { RBCs } \geq 6 \text { at } 24 \mathrm{~h}, \mathrm{n}(\%) \\
\text { Median PTr [IQR], points } \\
\text { Median INR [IQR], points } \\
\text { D30 observed mortality } \mathrm{n}(\%) \\
\text { Level } 2 \text { patients, } \mathrm{n}(\%)\end{array}$ & $\begin{array}{l}2(6) \\
15(44) \\
1.3[1.1-1.5] \\
1.3[1.2-1.5] \\
5(15) \\
19(56)\end{array}$ & $\begin{array}{l}26(32) \\
65(80) \\
1.7[1.4-2.0] \\
1.9[1.5-2.5] \\
30(37) \\
26(32)\end{array}$ & $\begin{array}{l}0.0059 \\
0.0003 \\
<0.0001 \\
<0.0001 \\
0.0313 \\
0.0296\end{array}$ \\
\hline TQ ratio > 1.2, $\mathrm{n}(\%)$ & $20(59)$ & $65(80)$ & 0.0312 \\
\hline Median SAPS II [IQR], points & $46[36-63]$ & $60[46-78]$ & 0.0039 \\
\hline Variables at $24 \mathrm{~h}$ & Low ratio $(\mathrm{N}=32)$ & High ratio $(\mathrm{N}=90)$ & $\mathrm{p}$ \\
\hline $\begin{array}{l}\text { RBCs } \geq 10 \text { at } 24 \mathrm{~h}, \mathrm{n}(\%) \\
\mathrm{RBCs} \geq 6 \text { at } 24 \mathrm{~h}, \mathrm{n}(\%) \\
\text { Median PTr [IQR], points } \\
\text { Median INR [IQR], points }\end{array}$ & $\begin{array}{l}2(6) \\
13(41) \\
1.3[1.2-1.5] \\
1.3[1.2-1.6]\end{array}$ & $\begin{array}{l}28(31) \\
71(79) \\
1.6[1.3-2.0] \\
1.8[1.4-2.4]\end{array}$ & $\begin{array}{l}0.0103 \\
0.0001 \\
0.0005 \\
0.0001\end{array}$ \\
\hline \multicolumn{4}{|c|}{ INR: International Normalized Ratio } \\
\hline \multicolumn{4}{|l|}{ PTr: Prothrombin Time ratio } \\
\hline \multicolumn{4}{|c|}{ SAPS II: Simplified Acute Physiology Score II } \\
\hline \multicolumn{4}{|l|}{ RBC: Red Blood Cell } \\
\hline IQR: Interquartile Range & & & \\
\hline
\end{tabular}


Table 4. Comparison of observed vs. predicted mortality at D30 according to ratio type and time.

\begin{tabular}{|llll|}
\hline Variables & $\begin{array}{l}\text { Observed mortality } \\
\mathbf{n}(\%)\end{array}$ & $\begin{array}{l}\text { Predicted mortality } \\
\mathbf{n}(\%)\end{array}$ & $\mathbf{p}$ \\
\hline High ratio & & & \\
\hline $6 \mathrm{~h}(\mathrm{n}=81)$ & $30(37)$ & $38(47)$ & 0.0036 \\
\hline $24 \mathrm{~h}(\mathrm{n}=90)$ & $30(33)$ & $39(43)$ & 0.0015 \\
\hline Low ratio & & & 0.0031 \\
\hline $6 \mathrm{~h}(\mathrm{n}=34)$ & $5(15)$ & $10(29)$ & 0.0030 \\
\hline $24 \mathrm{~h}(\mathrm{n}=32)$ & $6(19)$ & $11(34)$ & \\
\hline
\end{tabular}

\section{Figures}

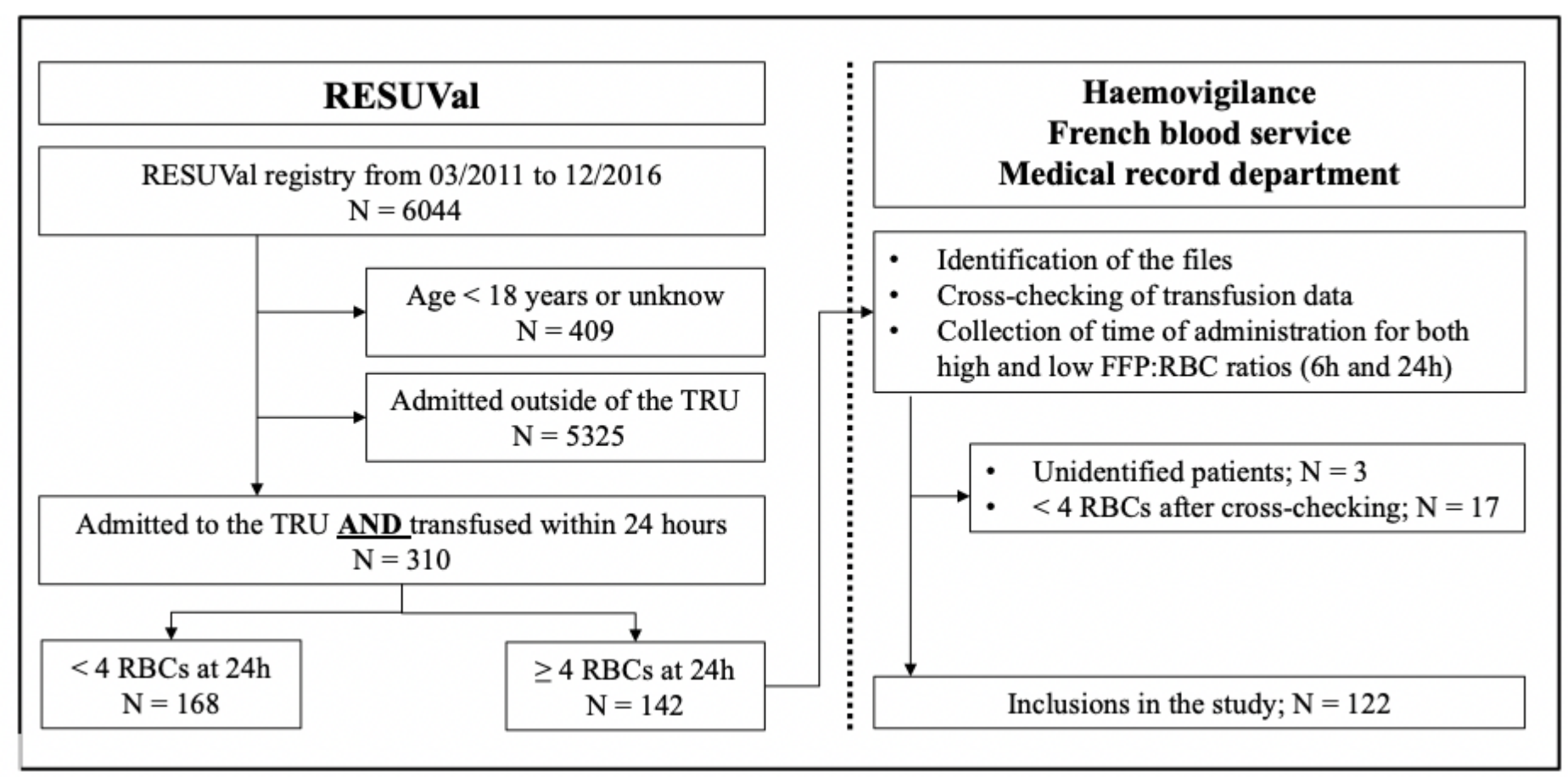

Figure 1

Study flow chart. RESUVal: emergency network of the Rhone Valley TRU: Trauma Resuscitation Unit RBC: Red Blood Cell FFP: Fresh Frozen Plasma 
ISS : $\square \quad 0-14 \square 15-30 \square 31-75$

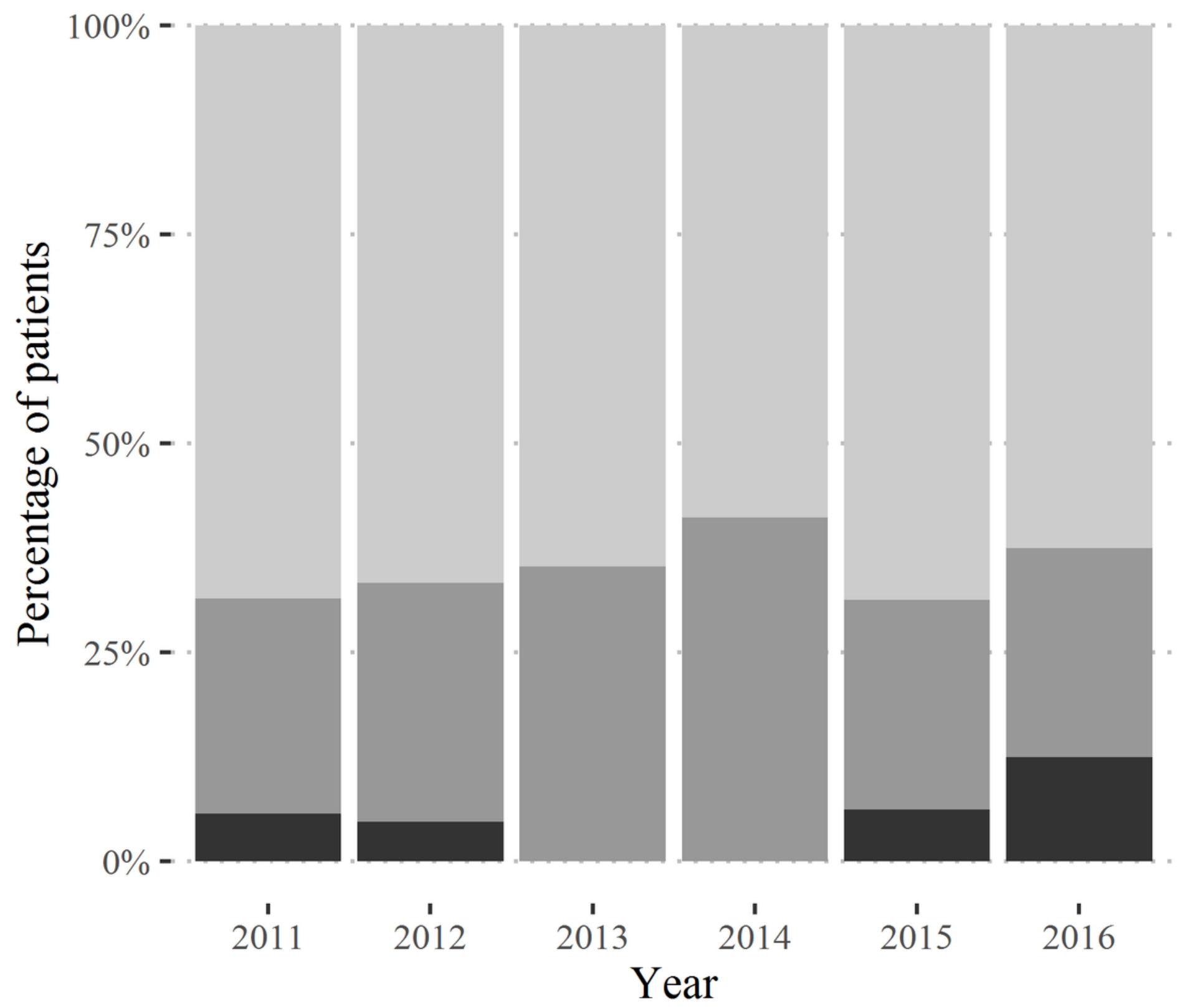

Figure 2

Annual proportion of patients according to the ISS. ISS: Injury Severity Score 


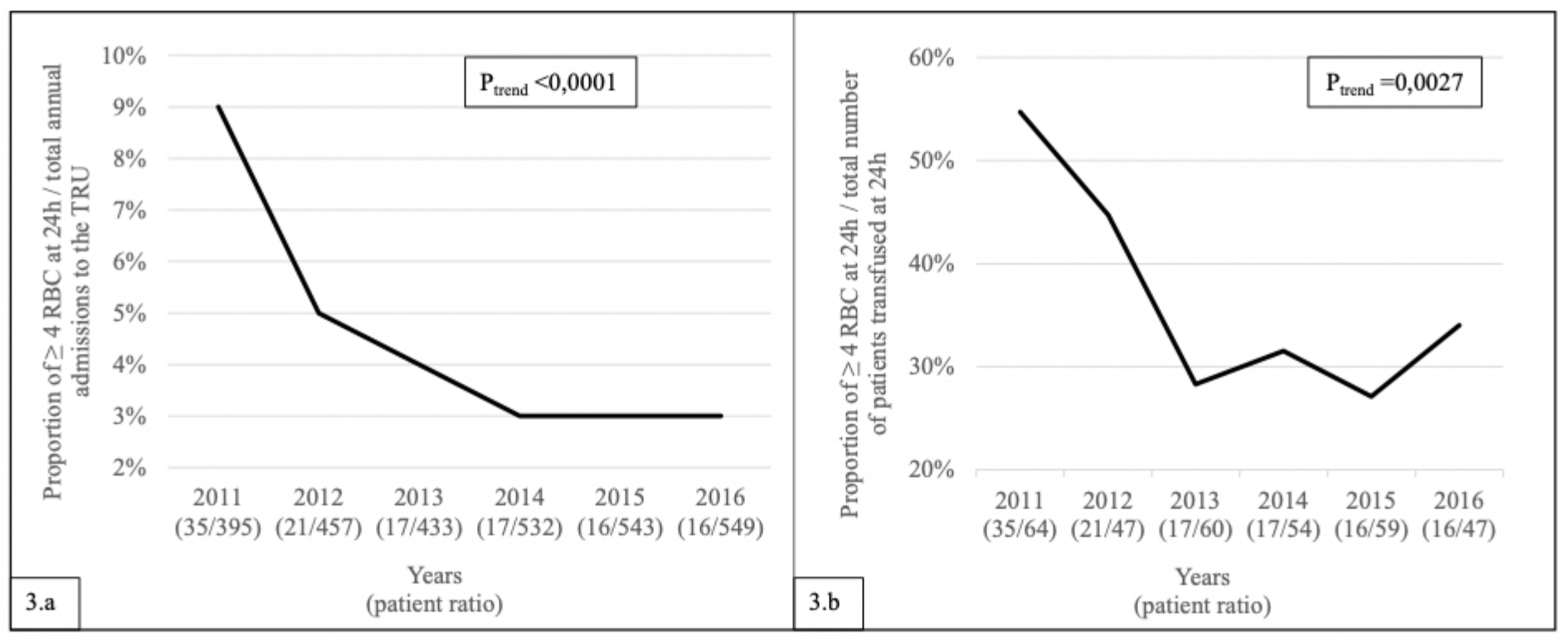

Figure 3

Decrease in the annual proportion of patients receiving at least 4 RBCs within the first $24 \mathrm{~h}$ after trauma. Proportion of patients in relation to the total annual admissions to the TRU (3.a) and compared to the total number of patients transfused at $24 \mathrm{~h}$ in the TRU (3.b). For each year, patient ratio is presented between brackets. TRU: Trauma Resuscitation Unit RBC: Red Blood Cell

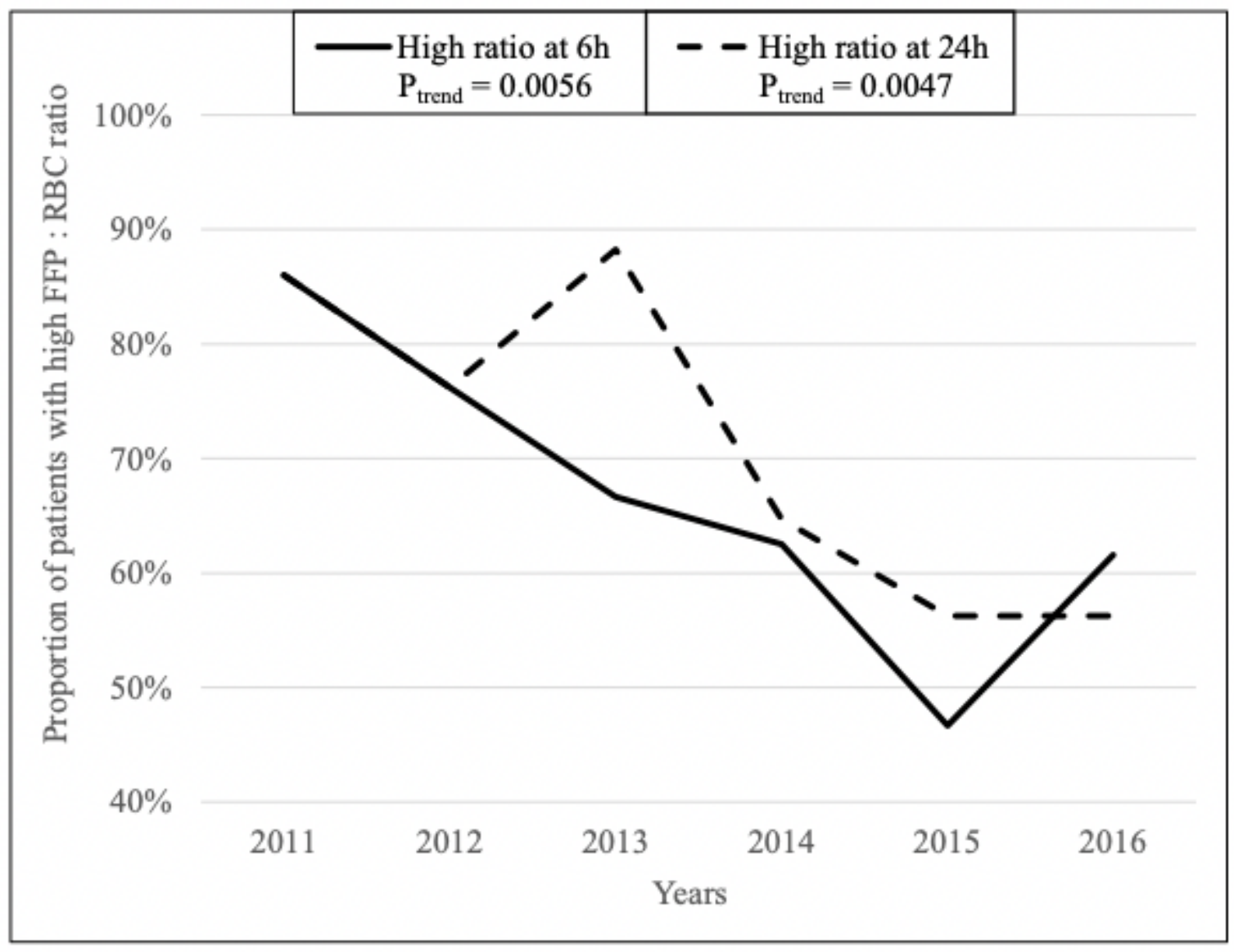


Figure 4

Proportion of patients with high FFP:RBC ratio at 6h and 24h between 2011 and 2016.

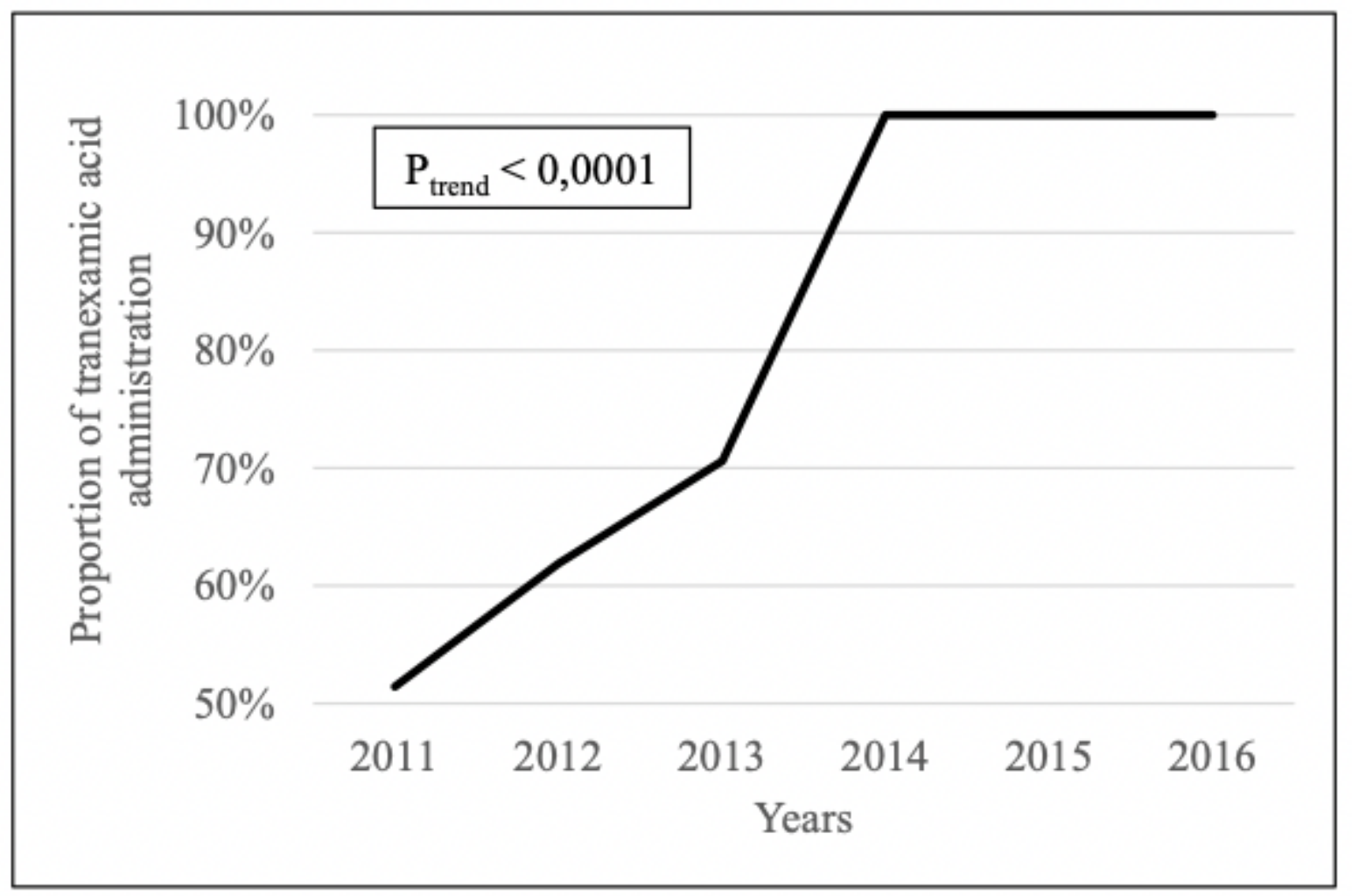

Figure 5

Proportion of patients administered with tranexamic acid between 2011 and 2016. RBC: Red Blood Cell

\section{Supplementary Files}

This is a list of supplementary files associated with this preprint. Click to download.

- Supplementaryfile.2.docx

- Supplementaryfile.1.docx 